\title{
A QUANTITATIVE ASSOCIATION BETWEEN SOIL MOISTURE CONTENT AND THE FREQUENCY OF THE CYANOGENIC FORM OF LOTUS CORNICULATUS L. AT BIRSAY, ORKNEY
}

\author{
RICHARD J. ABBOTT \\ Botany Department, St Andrews University, St Andrews, \\ Fife KY16 9AL, Scotiand
}

Received 6.xii.76

\begin{abstract}
SUMmary
A survey was conducted of the frequency of the cyanogenic form of Lotus corniculatus within a range of populations on Mainland, Orkney. Most populations were found to contain a high percentage of cyanogenic plants. Two exceptions were at Yesnaby and on the links at Birsay. A detailed study of populations on and off the Birsay Links revealed a highly significant quantitative association between soil moisture content and the frequency of the cyanogenic form.
\end{abstract}

\section{INTRODUCTION}

ENQUIRY into the factors which control the relative frequencies of cyanogenic and acyanogenic phenotypes within populations of Lotus corniculatus L. has indicated that several components of the environment may be important (see Ellis, Keymer and Jones, 1977). Soil moisture stress is considered to be one such selective factor (Foulds and Grime, 1972) though in certain conditions seems of no consequence (Jones, 1973; Ellis, et al., 1977). Here I report evidence of a highly significant quantitative association between soil moisture content and the frequency of the cyanogenic form of $L$. corniculatus within an exposed coastal region of Orkney.

\section{Materials and methods}

The first part of the study consisted of a broad survey of the polymorphism of cyanogenesis of L. corniculatus within a range of coastal and inland habitats throughout the western and central areas of Mainland, Orkney. From each of 14 locations (fig. 1 (a)) samples of 120 L. corniculatus plants were collected and tested for cyanogenesis by use of the modified picric acid paper technique (Daday, 1954). This technique has some shortcomings as it is insensitive to very low levels of HCN (Jones, 1966) and thus may tend to overestimate the frequency of the acyanogenic phenotype within populations. However, it is a convenient technique and one that is widely used in such field studies (Foulds and Grime, 1972; De Araújo, 1976). Sampling was carried out between 15-17 June 1976. Gare was taken to collect from discrete plants at least $1 \mathrm{~m}$ apart to prevent sampling the same clone more than once.

To follow up the initial survey a detailed study of the polymorphism was conducted on 18 June 1976 at Birsay, N.W. Mainland, Orkney. Within this area leaves from 90 plants of $L$. corniculatus were taken from each of seven sites (fig. 1 (b)) and tested for cyanogenesis. Again care was taken to sample separate clones. At the time of collection soil samples to a depth 

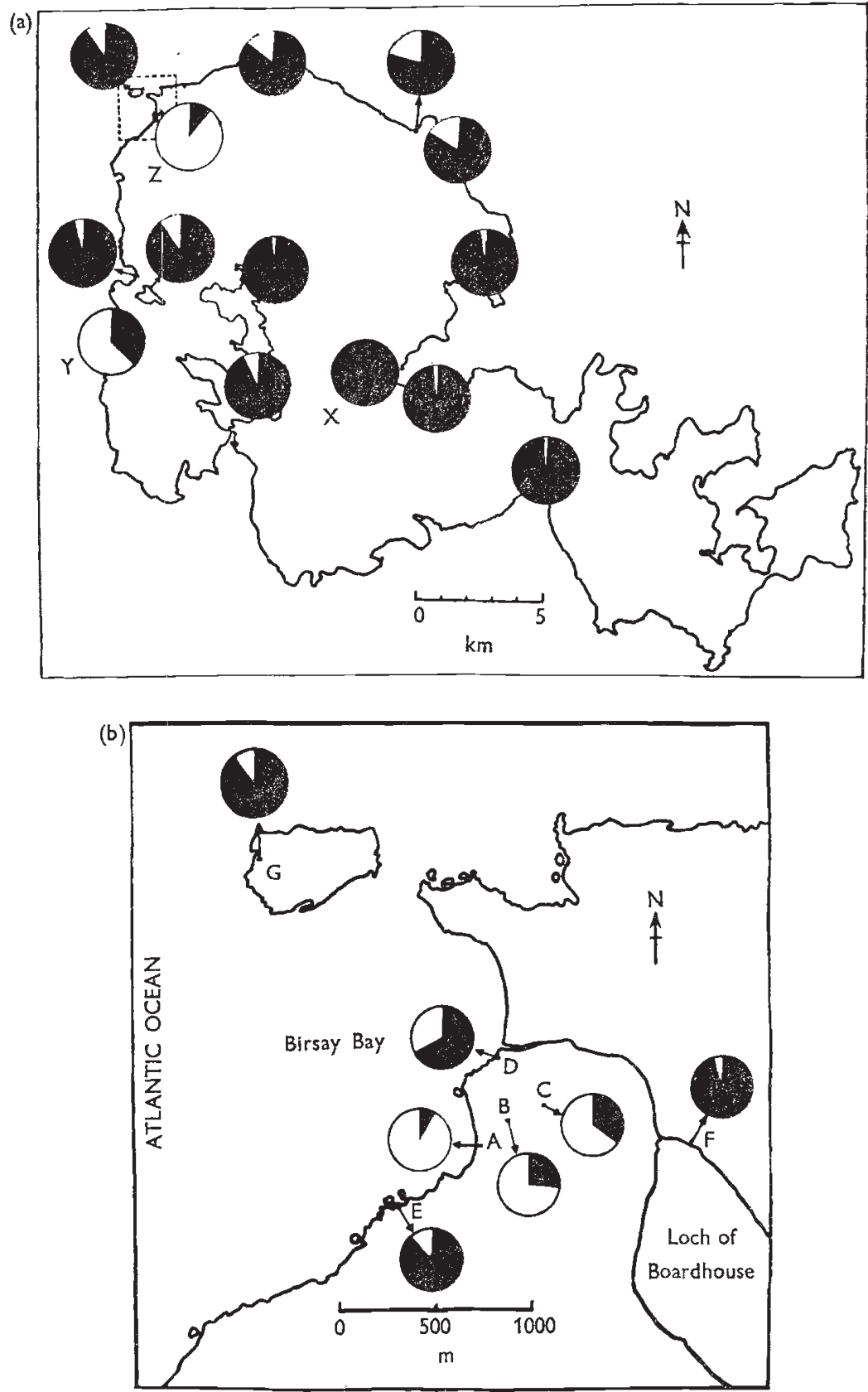

FIG. 1.-(a) The distribution of the cyanogenic form of Lotus corniculatus on Mainland, Orkney. (b) A map at enlarged scale of the area enclosed by the dashed rectangle in (a) showing the distribution of the cyanogenic form at Birsay. The black section of each circle (pie) indicates the frequency of the cyanogenic form. 
of $7.5 \mathrm{~cm}$ were taken from each of five sites by collecting random composite samples (after Jackson, 1958) within each site area. The water content of two samples from each site was determined by oven-drying at $100^{\circ} \mathrm{G}$ until there was no further change in weight.

\section{RESUltS AND Discussion}

From the initial survey it was apparent (fig. 1 (a)) that within most locations of the western and central areas of Mainland the cyanogenic phenotype was present at very high frequencies. Indeed at one site (" X" -Grid ref. HY352139) all plants sampled were cyanogenic. Two populations that were exceptions to the rule were at Yesnaby ("Y"-Grid ref. HX221159) and Birsay Links (" Z"-Grid ref. HX245273) where the cyanogenic phenotype was in the minority for plants sampled. Both Yesnaby and Birsay sites are very exposed to strong winds yet differ for other characters. The population at Yesnaby is from the top of high cliffs $(15 \mathrm{~m})$. A detailed analysis of the soils of this area (Harris, personal communication) shows that along a transect running from approximately 30 to $300 \mathrm{~m}$ inland from the cliff face, soil moisture content never falls below 50 per cent over the first $200 \mathrm{~m}$ while the percentage organic matter of oven-dried soils is always in excess of 30 per cent. In contrast the site at Birsay (" $\mathrm{Z}$ ") is situated on the sandy links (machair) approximately $5 \mathrm{~m}$ above sea level. Here soil moisture content was estimated as 2.52 per cent and the organic matter content is also likely to be low as the soil is almost entirely composed of pure sand.

The detailed survey of Birsay area (fig. 1 (b)) established the presence of a variety of population type. Indeed there occur sharp changes between

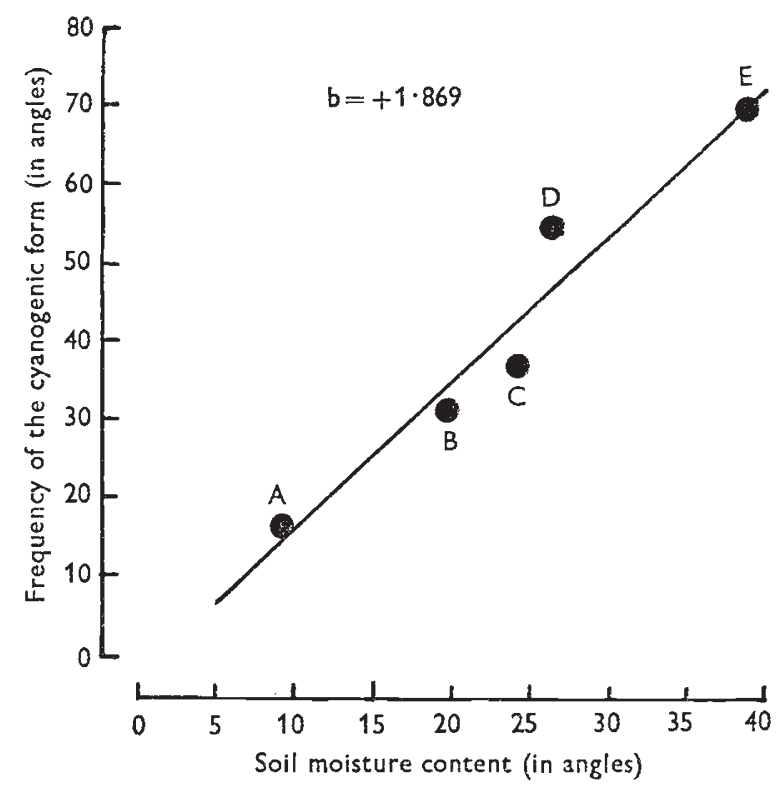

Fig. 2.-The frequency of the cyanogenic form of $L$. corniculatus for five populations at Birsay plotted against the soil moisture content of the respective sites. All values are in angles following transformation of percentages. 
populations in the frequency of the cyanogenic form over relatively short distances. Analysis by means of a $2 \times 7 \chi^{2}$ contingency table shows that the differences are significant at below the 0.001 level of probability, $\chi^{2}=274.5$ with 6 d.f. Populations from links' sites (A, B, G and D) contain less plants of the cyanogenic phenotype than populations from sites off the links ( $E, F$ and $G$ ). However, even on the links there are variations (fig. 1 (b)). Inland from site $\mathrm{A}$ the frequency of cyanogenic plants increases through site B to C. Site D close to the mouth of a stream lies within an area fenced off from the rest of the links and in deeper vegetation due to the lack of cattle grazing. This site contains a much greater proportion of cyanogenic phenotypes than the other links populations.

The possibility that variations in the level of exposure between sites is a cause of the observed differences in the frequency of the cyanogenic form (after Ellis et al., 1977) would seem unlikely at Birsay. Although no records of wind speed or salt deposition were taken it is clear that sites A, D, E and G are all very exposed to strong winds and the accompanying salt spray yet show marked differences in phenotypic composition. It seems that at Birsay soil moisture is the critical factor. A plot of the frequency of cyanogenic form against the soil moisture content of respective sites reveals a highly positive association (the fitted regression line is significant at the 0.01 level of probability, $t=6.32$ with 3 d.f.). This finding is particularly interesting in that it strongly suggests that quantitative variations in soil moisture content are matched by quantitative changes in the frequency of the cyanogenic phenotype within populations.

It remains to be established whether soil moisture content is the critical factor throughout Orkney. At Yesnaby ("Y") soil moisture content is high yet the frequency of cyanogenic phenotypes is low. Thus it would seem that here the relationship found at Birsay no longer holds. It seems clear from the results of this study and how they contrast with the findings of Ellis et al. (1977) that the ecological genetics of cyanogenesis is complex and requires further investigation.

Acknowledgments.-I am most grateful to James Bryce, Peter Gardiner, Gary Gray, Jerry Rowberry and Ian Smith for their help with field work and to Professor David Spence for organising the visit to Orkney. I am indebted to Stuart Corstorphine who prepared the maps and to Dr Mary Ellis and Professor David Jones, of the Unit of Genetics, University of Hull, for allowing me to read a final draft of the paper by Ellis, Keymer and Jones (1977) before going to press and for their comments on an earlier draft of the present paper.

\section{REFERENGES}

DADAY, H. 1954. Gene frequencies in wild populations of Trifolium repens L. I. Distribution by latitude. Heredity, $8,61-78$.

DE ARAÚJO, A. Ha 1976. The relationship between altitude and cyanogenesis in white clover (Trifolium repens, L.) Heredity, 37, 291-293.

ELLIS, W. M., KEYMER, R. J., AND JONES, D. A. 1977. On the polymorphism of cyanogenesis in Lotus corniculatus L. VIII. Ecological studies in Anglesey. Heredity (in press).

Foulds, w., AND GRIME, J. P. 1972. The influence of soil moisture on the frequency of cyanogenic plants in populations of Trifolium repens and Lotus corniculatus. Heredity, 28, 143-146.

Jackson, M. L. 1958. Soil Chemical Analysis. Constable, London.

JONES, D. A. 1966. On the polymorphism of cyanogenesis in Lotus corniculatus L. I. Selection by animals. Can. 7. Genet. Cytol., 8, 556-567.

JONES, D. A. 1973. Co-evolution and cyanogenesis. In Taxonomy and Ecology, ed. V. H. Heywood, pp. 213-242. Academic Press. 